\title{
Analysis of Factors Influencing Measurement Accuracy of Al Alloy Tensile Test Results
}

\author{
Bojan Podgornik ${ }^{1}$, Borut Žužek ${ }^{1}$, Marko Sedlaček ${ }^{1}$, Varužan Kevorkijan ${ }^{2}$, Boris Hostej ${ }^{2}$ \\ ${ }^{1}$ Institute of Metals and Technology, Lepi pot 11, 1000 Ljubljana, Slovenia, bojan.podgornik@imt.si \\ ${ }^{2}$ IMPOL R\&R d.o.o., Partizanska 38, 2310 Slovenska Bistrica, Slovenia
}

\begin{abstract}
In order to properly use materials in design, a complete understanding of and information on their mechanical properties, such as yield and ultimate tensile strength must be obtained. Furthermore, as the design of automotive parts is constantly pushed toward higher limits, excessive measuring uncertainty can lead to unexpected premature failure of the component, thus requiring reliable determination of material properties with low uncertainty.

The aim of the present work was to evaluate the effect of different metrology factors, including the number of tested samples, specimens machining and surface quality, specimens input diameter, type of testing and human error on the tensile test results and measurement uncertainty when performed on 2xxx series $\mathrm{Al}$ alloy. Results show that the most significant contribution to measurement uncertainty comes from the number of samples tested, which can even exceed $1 \%$. Furthermore, moving from experimental laboratory conditions to very intense industrial environment further amplifies measurement uncertainty, where even if using automated systems human error cannot be neglected.
\end{abstract}

Keywords: Measurement uncertainty, ultimate tensile strength, $\mathrm{Al}$ alloy, testing conditions.

\section{INTRODUCTION}

The growing demand for the reduction of pollution, more sever control of the emissions and better fuel-efficiency constitutes the driving force behind weight reduction in the automotive industry. The characteristic properties of aluminum and aluminum alloys make them one of the most important non-ferrous metals today [1] and the ideal candidates to replace heavier materials like steel in cars in order to respond to the weight reduction demands [2]. When compared to structural steels, aluminum alloys have much better strength to weight ratio, good formability, good corrosion resistance, as well as a good recycling potential, thus giving them a very broad field of application [3], [4]. $\mathrm{Al}-\mathrm{Cu}$ 2xxx series are high strength $\mathrm{Al}$ alloys which can be precipitation hardened to obtain high strengths, typically comparable to that of steel [5]. Hardening is achieved through the precipitation of $\mathrm{Al}_{2} \mathrm{Cu}$ or $\mathrm{Al}_{2} \mathrm{CuMg}$ intermetallic phases during ageing which leads to strengths inferior only to $7 \mathrm{xxx}$ series alloys [6]. Therefore, 2xxx series alloys are used for high strength structural applications such as aircraft fittings and wheels, military vehicles and bridges, forgings for trucks, cars and motorcycles, etc. These alloys are renowned also for their good machining characteristics, making them suitable for applications where hard extruded and machined parts are required [7].
In order to properly use materials in design, a complete understanding of and information on their mechanical properties, such as elastic modulus, yield and ultimate strengths, and elongation must be obtained. It is also vital to know how these properties are affected by the conditions of a specific application of the material. Factors such as the size of the part, surface condition, loading direction and loading rate may result in changes to these properties that must be considered in design [8]. Furthermore, as the design of automotive parts is constantly pushed toward the limits of the material, deviations from the defined material properties and excessive measuring uncertainty can lead to unexpected premature failure of the component [9]. Therefore, reliable determination of material strength, especially yield and ultimate tensile strength with low uncertainty is crucial when selecting material for automotive components.

Measurement results in science and industry, used as a base for publications, conformity check, decisions, designs as well as legal actions must be obtained under well-defined conditions and with sufficient accuracy and reliability. The simplest way to express the reliability of results is repeatability, described as a standard deviation and measurement uncertainty [10]. Over the last decades, various concepts and procedures of uncertainty evaluation were proposed and discussed [11]-[13]. With the publication of the Guide to the Expression of Uncertainty in 
Measurement (GUM), first published in 1993 and edited in 2008 [14], the importance of measurement uncertainty in the modern context of quality assurance has been recognized and a unified method for its evaluation and expression accepted worldwide [15]. Guidance on the estimation of measurement uncertainty can be obtained in different guides and normative documents [10], [12], [16], with the estimation of uncertainty for tensile strength measurement exemplified in [17].

Tensile tests are very common in industrial activities to evaluate the strength and ductility of metals and alloys. The specification of mechanical properties is essential for the adequate choice of materials, as well as for the design and manufacturing of components and products. Tensile properties define the behavior of material when subjected to stress, because they are related to the material's ability to resist or transmit the applied loads without breaking and without uncontrolled plastic deformation [12]. The mechanical properties of metals and alloys that are of engineering importance for structural design and can be obtained from the tensile test are: modulus of elasticity, yield strength at $0.2 \%$ offset, ultimate tensile strength, percent elongation and percent reduction in area at fracture [18].

The reference standard for performing tensile tests on metals at room temperature is ISO 6892-1:2009 [19]. The standard also states that measurement uncertainty analysis is useful for identifying major sources of inconsistencies of measured results. However, the major contribution to the uncertainty comes from the tested material [12]. On the other hand, variations in testing parameters, like temperature and strain rate have been found to have a large effect on uncertainty contribution not related to test equipment [18]. Other possible contributions relate to sample preparation and surface quality as well as to eventual human errors. The aim of the present work was to evaluate the effect of different metrology factors, including number of samples, specimens machining and surface quality, specimens input diameter, type of testing machine and human error on the tensile test results and measurement uncertainty when performed on 2xxx series $\mathrm{Al}$ alloy.

\section{SUBJECT \& METHODS}

\section{A. Statistical analysis and measurement uncertainty}

Measurement accuracy analysis of tensile test results included the calculation of average value $(\bar{x} ; 1)$, standard deviation $(\sigma ; 2)$, standard uncertainty $\left(u_{s} ; 3\right)$ and variability ( $b ; 4)$, defined by Levins et al. [20] as the range of values divided by the mean value. Analysis was performed for the three main tensile test parameters: ultimate tensile strength (UTS), yield strength (YS), and percent elongation (El).

$$
\begin{gathered}
\bar{x}=\frac{1}{n} \sum_{i=1}^{n} x_{i} \\
\sigma=\sqrt{\frac{\sum_{i=1}^{n} x_{i}-\bar{x}}{(n-1)}}
\end{gathered}
$$

$$
\begin{gathered}
u_{s}=\frac{\sigma}{\sqrt{n}} \\
b=\frac{x_{\max }-x_{\min }}{\bar{x}} \cdot 100
\end{gathered}
$$

Furthermore, ultimate tensile strength (UTS) and yield strength (YS) measurements were also analyzed in terms of measurement uncertainty and expanded uncertainty at the confidence level of $95 \%$ which were estimated according to the procedure given in [17].

Since input parameters are uncorrelated, the uncertainty connected with the determined UTS and YS is defined by general equation (5):

$$
u=\sqrt{\sum\left(c_{i} \cdot u_{i}\right)^{2}}
$$

where $c_{i}$ are sensitivity coefficients and $u_{i}$ standard uncertainties for individual components.

In the case of UTS (6), being function of the initial diameter of the specimen $\left(d_{0}\right)$ and maximum force $\left(F_{m}\right)$ recorded during the tensile test, measurement uncertainty $u(U T S)$ is calculated according to (7):

$$
\begin{gathered}
\text { UTS }=f\left(F_{m}, d_{0}\right)=\frac{4 \cdot F_{m}}{\pi \cdot d_{0}^{2}} \\
u(U T S)=\sqrt{\left(\frac{4}{\pi \cdot d_{0}^{2}}\right)^{2} \cdot u^{2}\left(F_{m}\right)+\left(-\frac{8 \cdot F_{m}}{\pi \cdot d_{0}^{3}}\right)^{2} \cdot u^{2}\left(d_{0}\right)}
\end{gathered}
$$

The uncertainty for measurement of the specimen diameter $\left(u\left(d_{0}\right)\right)$ is calculated on the basis of the arithmetical means for the series of six measurements, with the t-Student distribution assigned (8) and t-factor selected depending on the confidence level [17], [21], [22], or on the basis of the micrometer resolution (9), whichever value is higher.

$$
\begin{gathered}
u\left(d_{0}\right)_{A}=t \cdot \sqrt{\frac{\sum\left(d_{0 i}-\bar{d}_{o}\right)^{2}}{n(n-1)}} \\
u\left(d_{0}\right)_{B}=\frac{0.01}{2 \cdot \sqrt{3}}
\end{gathered}
$$

Major factors that affect total uncertainty of measurement of the maximum force include uncertainty of the measurement of the force, attributable to the dynamometer of the tensile test machine, zero adjustment in the force measuring part, possible misalignment of the force applied, ambient temperature during test and rate of the load application. The error that results from these factors for class 1 machine used in this investigation was evaluated to $\pm 0.5 \%$ [23]. Therefore, the uncertainty for measurement of the maximum force can be calculated according to (10): 


$$
u\left(F_{m}\right)=\frac{0.005 \cdot F_{m}}{\sqrt{3}}
$$

In the case of yield strength (YS) measurement uncertainty $u(Y S)$ is calculated according to (11):

$$
u(Y S)=\sqrt{\left(\frac{4}{\pi \cdot d_{0}^{2}}\right)^{2} \cdot u_{c}^{2}\left(F_{0.2}\right)+\left(-\frac{8 \cdot F_{0.2}}{\pi \cdot d_{0}^{3}}\right)^{2} \cdot u^{2}\left(d_{0}\right)}
$$

with the overall uncertainty for measurement of the force $F_{0.2}$, resulting from uncertainty of the force measurement (10), recording frequency during measurement and inclination of the linear section of the $\sigma-\varepsilon$ curve described by $F_{0.2 E}=\Delta F / \Delta \varepsilon(\varepsilon-0.002)$, being defined as (12) and (13):

$$
\begin{gathered}
u_{c}\left(F_{0.2}\right)=\sqrt{u^{2}\left(F_{0.2}\right)+u^{2}\left(\Delta F_{0.2}\right)+u^{2}\left(F_{0.2 E}\right)} \\
u\left(\Delta F_{0.2}\right)=\frac{F_{0.2(1)}-F_{0.2(2)}}{2 \cdot \sqrt{3}}=0.0015 \\
u\left(F_{0.2 E}\right)=\sqrt{u\left(F_{0.2 E}\right)_{1}+u\left(F_{0.2 E}\right)_{2}} \\
u\left(F_{0.2 E}\right)_{1}=\left(\frac{\varepsilon-0.002}{\Delta \varepsilon}\right)^{2} \cdot u^{2}(\Delta F) \\
u\left(F_{0.2 E}\right)_{2}=\left(-\frac{\Delta F \cdot(\varepsilon-0.002)}{(\Delta \varepsilon)^{2}}\right)^{2} \cdot u^{2}(\Delta \varepsilon) \\
u(\Delta F)=\sqrt{u^{2}\left(F_{\max }\right)+u^{2}\left(F_{\min }\right)}
\end{gathered}
$$

where $u(F)$ is calculated according to (10).

$$
\begin{gathered}
u(\Delta \varepsilon)=\sqrt{u^{2}\left(\varepsilon_{\max }\right)+u^{2}\left(\varepsilon_{\min }\right)} \\
\text { where } u(\varepsilon)=\frac{K_{\varepsilon} \cdot \varepsilon}{\sqrt{3}}
\end{gathered}
$$

and $K_{\varepsilon}$ extensometer accuracy

$\mathrm{F}_{0.2(1)}$ is the closest value of force during automatic measurement that was higher than $\mathrm{F}_{0.2}$ and $\mathrm{F}_{0.2(2)}$ the closest value of force lower than $\mathrm{F}_{0.2} ; \mathrm{F}_{\max }, \mathrm{F}_{\min }, \varepsilon_{\max }$ and $\varepsilon_{\min }$ relate to maximum and minimum values recorded during automatic measurement.

Finally, according to [17] the expanded uncertainty at the confidence level of $95 \%$ is calculated as (14):

$$
U(x)=2 \cdot \sqrt{u^{2}(x)+\left(t \cdot u_{s}(x)\right)^{2}}
$$

\section{B. Material}

Material used in this investigation for tensile test results uncertainty analysis was 2030 series $\mathrm{Al}$ alloy $\mathrm{AlCu} 4 \mathrm{PbMg}$, with the following chemical composition (wt \%): $0.43 \% \mathrm{Si}$, $0.45 \% \mathrm{Fe}, 3.7 \% \mathrm{Cu}, 0.56 \mathrm{Mn}, 0.83 \% \mathrm{Mg}, 0.06 \% \mathrm{Cr}$, 0.09 \% Zn, $0.1 \%$ Ti, $0.9 \%$ Pb, 0.12\% Bi and 0.08 Sn. From single charge extruded rods $(\phi 20 \mathrm{~mm})$, delivered in $\mathrm{T} 1$ condition, type A tensile test specimens (DIN 50125:200907 ) with a nominal diameter of $10 \mathrm{~mm}$ were machined. Two sets of machining parameters were used, one representing laboratory conditions (ML; cutting speed $3.0 \mathrm{~m} / \mathrm{s}$, feed rate $0.08 \mathrm{~mm} / \mathrm{rev}$, depth of cut $1 \mathrm{~mm}$ ) and one industrial practice $\left(\mathrm{MI} ; v_{c}=2.5 \mathrm{~m} / \mathrm{s}, f=0.12 \mathrm{~mm} / \mathrm{rev}, \mathrm{d}_{\mathrm{c}}=1.8 \mathrm{~mm}\right)$, which resulted in an average surface roughness of $R_{a}=0.55 \mu \mathrm{m}$ and $0.45 \mu \mathrm{m}$, respectively. For each experiment up to 15 tensile test samples were used. Tensile testing was performed at room temperature according to ISO 68921:2009 B20 standard [19]. For comparative purposes tests were carried out by two class 1 tensile test machines, Instron 8802 used as a laboratory single operator manipulated machine, and Zwick Z250 as an industrial fully automated system.

\section{RESUlts \& DisCUSSION}

\section{A. Number of samples}

Typical stress-strain curve for the tested Al alloy is shown in Fig.1. When using 15 industrially machined samples (MI) and laboratory Instron 8802 machine, average measured ultimate tensile strength (UTS) was $487.1 \mathrm{MPa}$, yield strength (YS) $345.3 \mathrm{MPa}$ and elongation (El) $16.2 \%$. Corresponding values for standard deviation $(\sigma)$, standard uncertainty $\left(\mathrm{u}_{\mathrm{s}}\right)$, and variability (b) for different number of tested samples taken into account are given in Table 1.

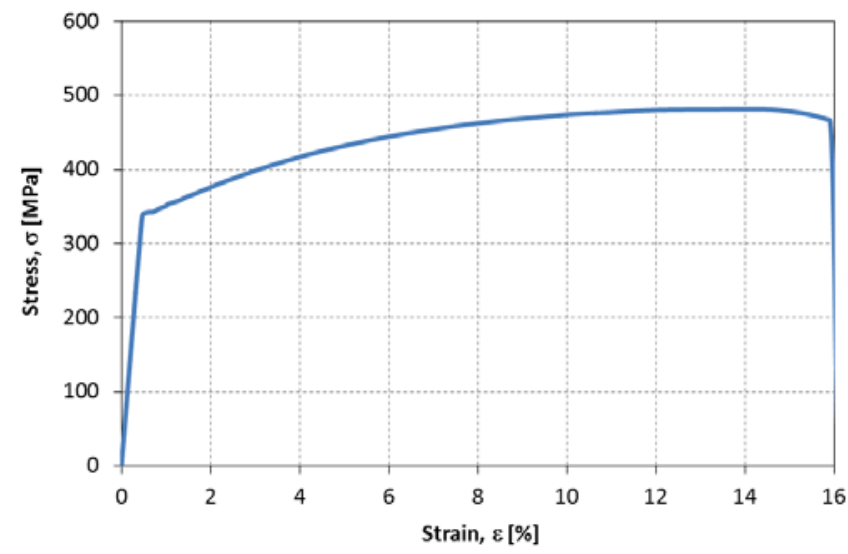

Fig.1. Typical stress-strain curve for tested AlCu4PbMg alloy.

By excluding maximum and minimum measured value, thus taking into account unexpected defects in the material, average values for all three tensile test parameters remained unchanged, however, standard deviation, uncertainty and variability were reduced by about $10 \%$, as shown in Fig.2. Fig.2. also shows effect of the number of samples tested on tensile test results and their deviation and uncertainty. Analysis was performed by using randomly selected 10, 6 or 
3 results from 15 samples test and determining the largest deviations. Reducing the number of samples tested may or may not reflect in change in the average value of the tensile properties evaluated, with the variation in the present case being in the range of $\pm 1.5 \%$. However, reduced number of samples tested has a considerable influence on the standard deviation and uncertainty of the measured values.

Table 1. Effect of number of samples on tensile test results.

\begin{tabular}{|c|c|c|c|c|c|c|}
\hline \multirow{2}{*}{ Parameter } & \multicolumn{5}{|c|}{ Number of samples } \\
\cline { 2 - 7 } & $\mathbf{1 5}$ & $\mathbf{1 5}$ & $\mathbf{1 0}$ & $\mathbf{6}$ & $\mathbf{3}$ \\
\hline \multirow{4}{*}{ YS } & $\bar{x}[\mathrm{MPa}]$ & 345.3 & 345.3 & $\begin{array}{c}344.3- \\
346.5\end{array}$ & $341.7-$ & $340.7-$ \\
& $\sigma[\mathrm{MPa}]$ & 3.74 & 3.35 & 4.62 & 5.50 & 350.7 \\
\cline { 2 - 7 } & $\mathrm{u}_{\mathrm{s}}[\mathrm{MPa}]$ & 0.96 & 0.93 & 1.46 & 2.25 & 3.67 \\
\cline { 2 - 7 } & $\mathrm{b}[\%]$ & 3.19 & 2.9 & - & - & - \\
\hline \multirow{4}{*}{ UTS } & $\bar{x}[\mathrm{MPa}]$ & 487.1 & 487.2 & $485.0-$ & $483.5-$ & $482.3-$ \\
& $\sigma[\mathrm{MPa}]$ & 3.64 & 3.36 & 4.43 & 5.14 & 5.78 \\
\cline { 2 - 7 } & $\mathrm{u}_{\mathrm{s}}[\mathrm{MPa}]$ & 0.94 & 0.93 & 1.40 & 2.10 & 3.34 \\
\cline { 2 - 7 } & $\mathrm{b}[\%]$ & 2.05 & 2.05 & - & - & - \\
\hline \multirow{4}{*}{ El } & $\bar{x}[\%]$ & 16.21 & 16.21 & $16.16-$ & $16.14-$ & $16.03-$ \\
& & & & 16.25 & 16.33 & 16.40 \\
\cline { 2 - 7 } & $\sigma[\%]$ & 0.19 & 0.17 & 0.24 & 0.27 & 0.35 \\
\cline { 2 - 7 } & $\mathrm{u}_{\mathrm{s}}[\%]$ & 0.05 & 0.05 & 0.08 & 0.11 & 0.20 \\
\cline { 2 - 7 } & $\mathrm{b}[\%]$ & 3.70 & 3.08 & - & - & - \\
\hline
\end{tabular}

* maximum and minimum values excluded
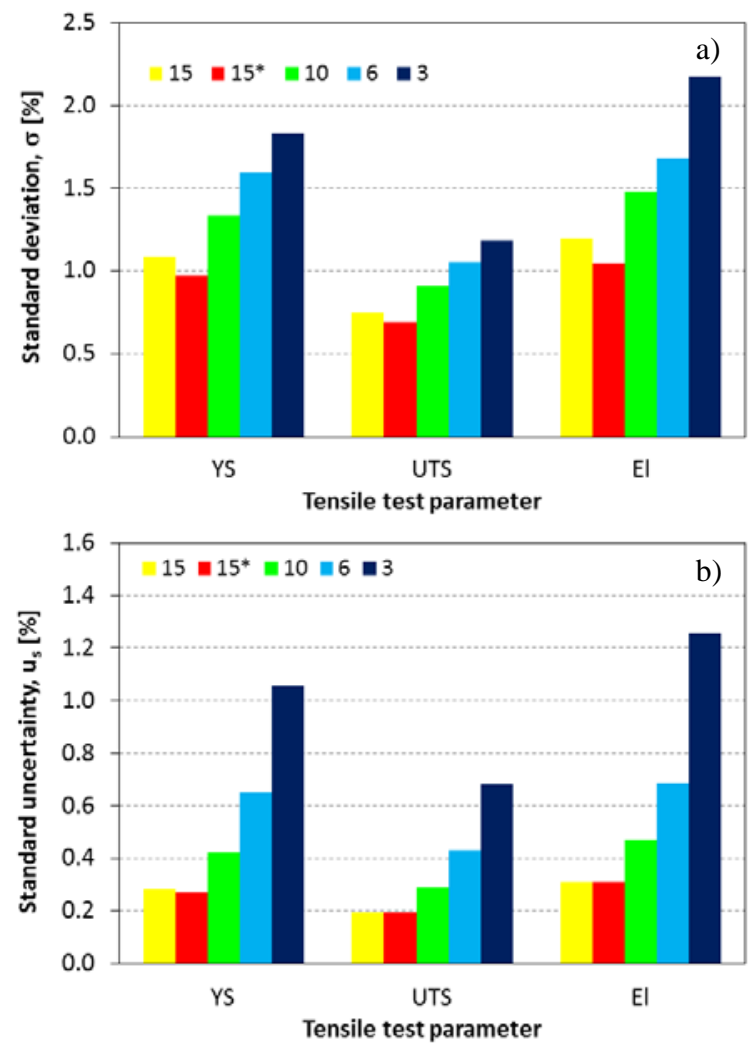

Fig.2. Effect of number of samples tested on a) standard deviation and b) standard uncertainty; values given in \% of average value.
By reducing the number of tested samples from 15 to 10, standard deviation increased for $\sim 25 \%$ and standard uncertainty for $\sim 50 \%$. Further decrease in the number of tested samples to 6 or even down to 3 increased standard deviation for $50 \%$ and $135 \%$ and standard uncertainty for over $70 \%$ and $250 \%$, respectively. In order to ensure sufficient measuring accuracy with standard uncertainty below $2 \%$ minimum number of samples required should be 6-10.

\section{B. Diameter measurement accuracy}

Measured yield and ultimate tensile strength values depend on the load vs. strain recording and initial diameter of the test specimen, provided and measured by the machine operator. Test specimen diameter can be given as a minimum or average value of at least three measurements. However, diameter measurement accuracy influences the final YS and UTS values. As shown in Fig.3., increase in diameter measurement uncertainty $\left(\mathrm{u}\left(\mathrm{d}_{0}\right)\right.$; 9$)$ from $0.05 \%$ to $0.1 \%(0.005 \mathrm{~mm}$ in the present case) will result in increased UTS and YS measurement uncertainty of about $0.05 \%$, while diameter measurement uncertainty of $0.5 \%$ already leads to UTS and YS measurement uncertainty of over $1 \%$ and $1.5 \%$, respectively.

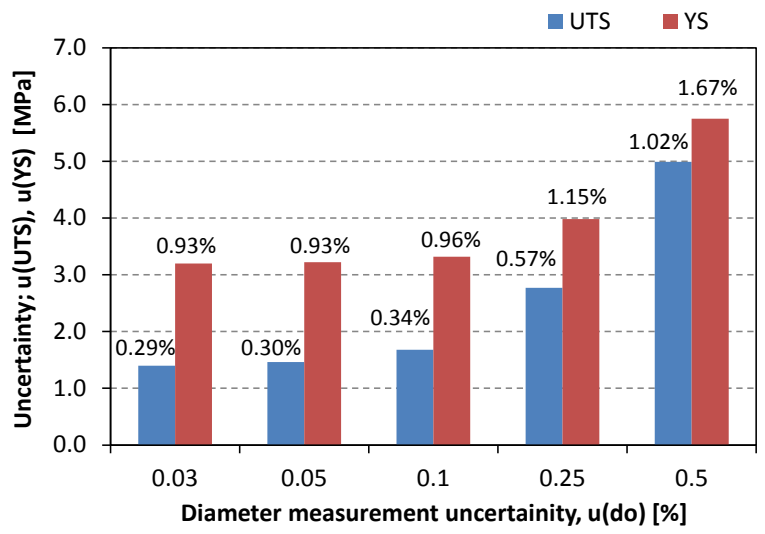

Fig.3. Effect of diameter measurement uncertainty on YS and UTS measurement uncertainty.

\section{Samples preparation}

Surface quality of parts, components and test specimens is affected by machining conditions. However, it may also influence the mechanical properties [24]. In the present investigation, changing feed rate and depth of cut from mild laboratory conditions (ML) to more severe industrial conditions (MI) although giving lower average surface roughness resulted in slight drop in average tensile properties and in increased standard deviation, standard uncertainty and variability, as shown in Table 2. YS dropped for $\sim 0.72 \%$ from 348 to $345 \mathrm{MPa}$, UTS for $\sim 0.70 \%$ from 490 to $487 \mathrm{MPa}$ and elongation for $\sim 0.80 \%$ from 16.3 to $16.2 \%$. On the other hand, increase in standard deviation, standard uncertainty and variability caused by more severe machining conditions was more than two-fold. 
Table 2. Uncertainty related to machining conditions; 15 tensile test specimens tested on Instron 8802 machine.

\begin{tabular}{|c|c|c|c|}
\hline \multirow{2}{*}{} & \multicolumn{3}{|c|}{ ML } \\
\cline { 2 - 4 } & YS & UTS & El \\
\hline $\bar{x}$ & $348 \mathrm{MPa}$ & $490 \mathrm{MPa}$ & $16.3 \%$ \\
\hline$\sigma$ & $\begin{array}{c}1.57 \mathrm{MPa} \\
(0.45 \%)\end{array}$ & $\begin{array}{c}1.46 \mathrm{MPa} \\
(0.30 \%)\end{array}$ & $\begin{array}{c}0.22 \% \\
(1.35 \%)\end{array}$ \\
\hline \multirow{2}{*}{$\mathrm{u}_{\mathrm{s}}$} & $0.40 \mathrm{MPa}$ & $0.38 \mathrm{MPa}$ & $0.06 \%$ \\
& $(0.12 \%)$ & $(0.08 \%)$ & $(0.37 \%)$ \\
\hline $\mathrm{b}$ & $1.15 \%$ & $1.02 \%$ & $3.28 \%$ \\
\hline & \multicolumn{3}{|c|}{$\mathbf{M I}$} \\
\cline { 2 - 4 } & $\mathbf{Y S}$ & $\mathbf{U T S}$ & $\mathbf{E l}$ \\
\hline $\bar{x}$ & $345 \mathrm{MPa}$ & $487 \mathrm{MPa}$ & $16.2 \%$ \\
\hline$\sigma$ & $3.74 \mathrm{MPa}$ & $3.64 \mathrm{MPa}$ & $0.19 \%$ \\
& $(1.08 \%)$ & $(0.75 \%)$ & $(1.17 \%)$ \\
\hline $\mathrm{u}_{\mathrm{s}}$ & $0.96 \mathrm{MPa}$ & $0.94 \mathrm{MPa}$ & $0.05 \%$ \\
& $(0.28 \%)$ & $(0.19 \%)$ & $(0.31 \%)$ \\
\hline $\mathrm{b}$ & $3.19 \%$ & $2.05 \%$ & $3.70 \%$ \\
\hline
\end{tabular}

\section{Testing machine}

Testing conditions and requirements in experimental laboratories differ from the ones in industrial laboratories, where a lot of specimens of different size, shape and quality need to be tested every day. The numbers of tested samples can go to several hundred every day. This requires different testing machines which allow measurement procedure to be fully automated, including specimen's fixturing, positioning of the extensometer and machine control.

In the present investigation experimental laboratory conditions were simulated by using manually operated load controlled Instron 8802 machine (Fig.4.a), where each specimen was mounted and extensometer positioned manually by a single operator. For specimen mounting designated hydraulic cylindrical specimen's wedge action grips were used. On the other hand, fully automated position controlled Zwick Z250 machine (Fig.4.b) with universal hydraulic fixturing system and automatic extensometer was used in real industrial environment. In this case tensile tests were carried out by several operators. In both cases class 0.5 contact extensometers and class 1 force gauges with accuracy of $0.6 \%$ were used.

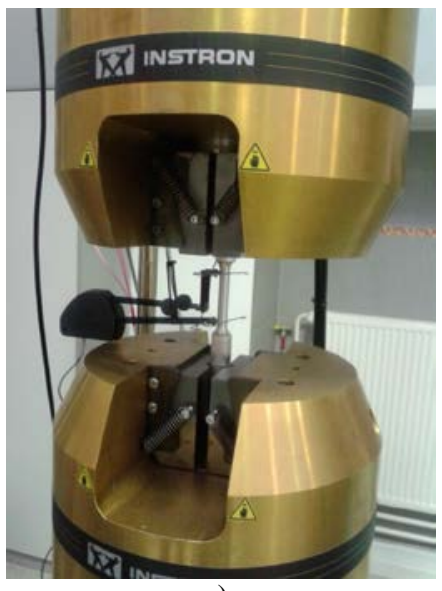

a)

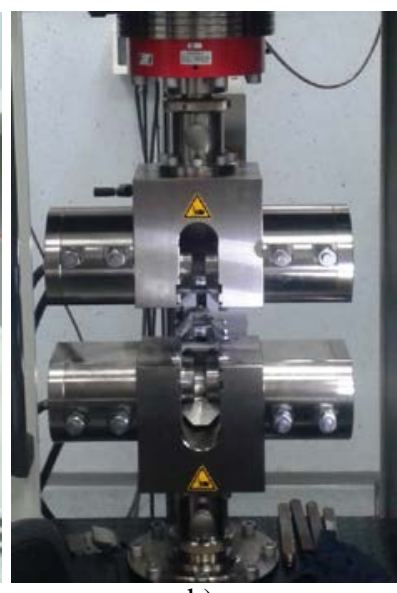

b)
Fig.4. a) Instron 8802 and b) Zwick Z250 test setup.
Results for manual laboratory measurements carried out on Instron 8802 machine by using 15 precisely machined tensile test specimens (ML) are given in Table 2. and shown in Fig.5. For the $\mathrm{Al}$ alloy investigated average YS was $348 \mathrm{MPa}$, with the standard deviation of $1.6 \mathrm{MPa}$, standard uncertainty $0.4 \mathrm{MPa}$ and variability of $1.2 \%$. Similar deviation and uncertainty were obtained also in the case of UTS, displaying average value of $490 \mathrm{MPa}$, while about one order of magnitude larger deviation was observed for elongation. By switching to automatic Zwick Z250 machine operated in industrial environment by different operators and again using 15 ML specimens, lower tensile properties were measured for the investigated $\mathrm{Al}$ alloy. In general, UTS and YS measured were lower for about $1 \%$ and El even up to $7 \%$ (Fig.5.). Furthermore, as shown in Fig.5., fully automatic measurement resulted in increased uncertainty when compared to experimental laboratory test, not so much when it comes to UTS, but extensively for YS and El. For YS standard deviation, standard uncertainty and variability doubled, while for El impairment tripled.

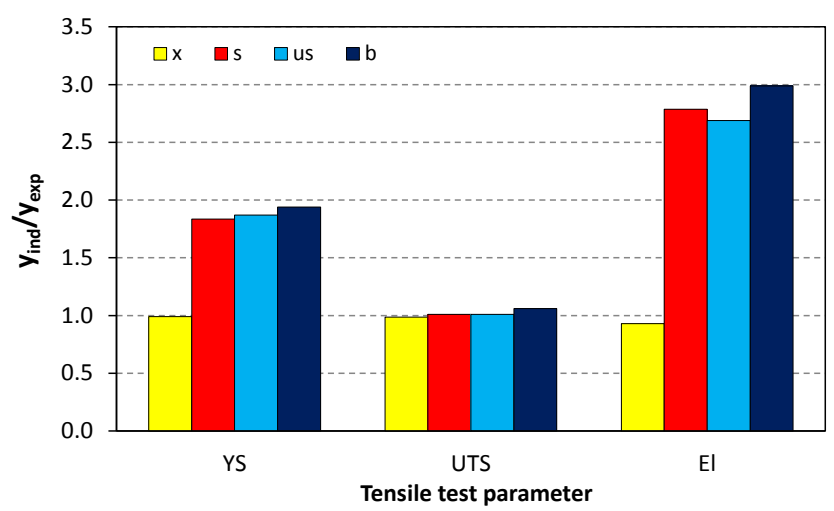

Fig.5. Comparison of measurements carried in experimental and industrial laboratory conditions.

\section{E. Human error}

In order to evaluate the effect of human error on tensile test results five groups of measurements were performed under conditions similar to real situation. Each set of measurements was carried out by Zwick Z250 machine on 10 industrially machined samples, performed at different days and different periods of the day (beginning/middle/end of week, morning/afternoon). Statistical analysis of the measured YS, UTS and El is shown in Fig.6.

The smallest variation in measured average values can be observed for measurements carried out in the morning time during the first half of the week. Standard deviation for YS was $0.3-0.4 \%$, for UTS $0.2-0.3 \%$ and for $\mathrm{El} \sim 2.8 \%$, and standard uncertainty for YS $\sim 0.10 \%$, for UTS $\sim 0.05 \%$ and El $\sim 0.75 \%$. In the afternoon standard deviation and uncertainty increased for YS and UTS to about $0.6 \%$ and $0.15 \%$ and for El up to $\sim 4 \%$ and $\sim 1 \%$, respectively. However, the biggest deviations were found for measurements performed at the end of the week, with the standard deviation for YS and UTS increasing up to $0.8 \%$ and standard uncertainty up to $0.2 \%$. 

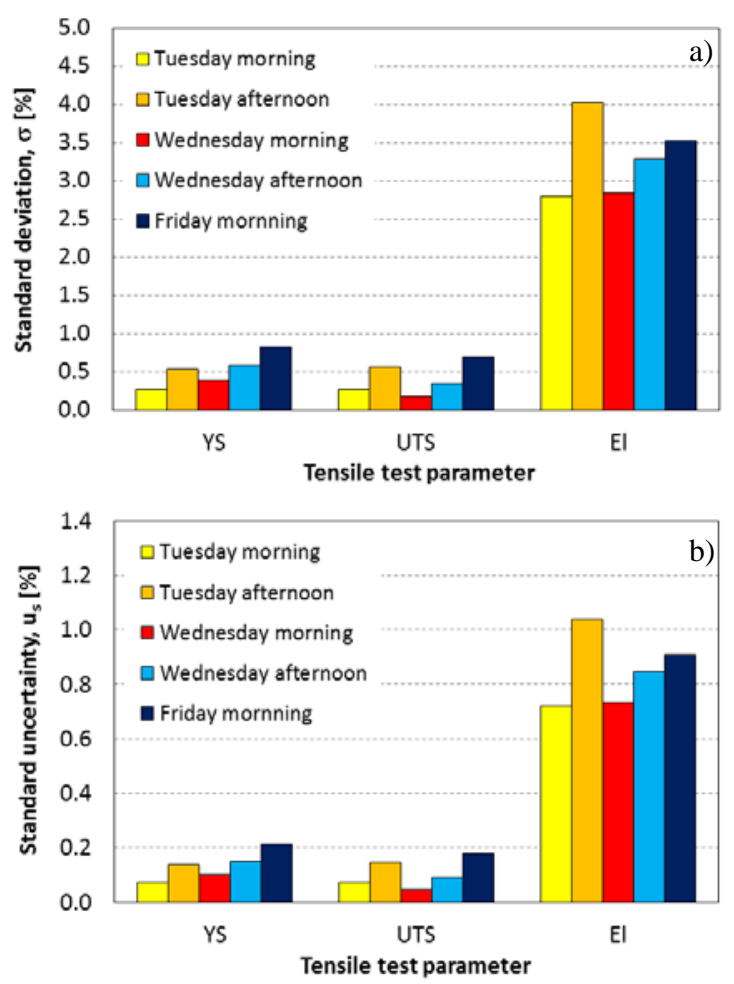

Fig.6. Measurement deviations related to testing time and day of the week; a) standard deviation and b) standard uncertainty.

\section{F. Measurement uncertainty}

Measurement uncertainty for the two testing machines used in this investigation was calculated according to procedure described in Chapter 2. On the basis of the resolution of the micrometer, the used uncertainty for measurement of the specimen diameter $\left(u\left(d_{0}\right) ; 9\right)$ is equal to $0.003 \mathrm{~mm}$, and increases to $0.014 \mathrm{~mm}$ if specimen diameter error of $0.5 \%$ is taken into account. For both testing machines, being in class 1 , force measurement uncertainty is calculated according to (10), which in the present case for maximum force $\left(\mathrm{F}_{\mathrm{m}}\right)$ is approx. $110 \mathrm{~N}$ and for $\mathrm{F}_{0.2}$ equal to $78 \mathrm{~N}$. Force measurement uncertainty related to recording frequency $\left(\mathrm{u}\left(\Delta \mathrm{F}_{0.2}\right) ; 13 \mathrm{a}\right)$ is $1.5 \mathrm{~N}$ and component related to inclination of the linear section of the $\sigma-\varepsilon$ curve $\left(\mathrm{u}\left(\mathrm{F}_{0.2 \mathrm{E}}\right)\right.$; $13 \mathrm{~b})$, taking into account class 0.5 extensometers equal to $240 \mathrm{~N}$. Thus, overall uncertainty for measurement of the force $\mathrm{F}_{0.2}\left(\mathrm{u}_{\mathrm{c}}\left(\mathrm{F}_{0.2}\right) ; 12\right)$ is about $250 \mathrm{~N}$. By summarizing all uncertainty components, measurement uncertainty related to ultimate tensile strength (u(UTS)) is $1.4 \mathrm{MPa}$ and related to yield strength (u(YS)) $3.2 \mathrm{MPa}$, if sample diameter error of $0.1 \%$ is taken into account. Increasing this error to $0.5 \%$ increases measurement uncertainty u(UTS) and u(YS) to 2.0 and 3.4 MPa, respectively (Table 3.).

The relative expanded uncertainties at the confidence level of $95 \%(k=2 ; 14)$, taking into account also the number of samples tested and $\mathrm{u}\left(\mathrm{d}_{\mathrm{o}}\right)=0.03 \%$, are given in Table 3 . For measurements performed on 15 industrially machined samples expanded measurement uncertainty for YTS is 3.5 $\mathrm{MPa}$ and for YS 6.7 MPa. By reducing the number of samples down to 10,6 or even to 3, expanded measurement uncertainty for UTS increased to 9.3 MPa and for YS even up to $11.6 \mathrm{MPa}$. These results clearly show the importance of the number of samples tested, with the minimum of at least 10 samples required to assure measurement uncertainty within $\pm 1 \%$.

Table 3. Measurement uncertainty and expanded measurement uncertainty results.

\begin{tabular}{|l|c|c|}
\hline \multirow{2}{*}{ Par. } & \multicolumn{2}{|c|}{ Measurement uncertainty $\mathrm{u}(\mathrm{x}) ;(7 \& 11)$} \\
\cline { 2 - 3 } & $\mathrm{d}_{0} \pm 0.1 \%$ & $\mathrm{~d}_{0} \pm 0.5 \%$ \\
\hline YS & $\pm 3.2 \mathrm{MPa}$ & $\pm 3.4 \mathrm{MPa}$ \\
\hline UTS & $\pm 1.4 \mathrm{MPa}$ & $\pm 2.0 \mathrm{MPa}$ \\
\hline
\end{tabular}

\begin{tabular}{|c|c|c|c|c|}
\hline \multirow[b]{2}{*}{ Par. } & \multicolumn{4}{|c|}{ Expanded measurement uncertainty U(x); (14) } \\
\hline & $\begin{array}{l}\mathrm{n}=15 \\
\mathrm{t}=1.04\end{array}$ & $\begin{array}{c}\mathrm{n}=10 \\
\mathrm{t}=1.06\end{array}$ & $\begin{array}{c}n=6 \\
t=1.14\end{array}$ & $\begin{array}{c}\mathrm{n}=3 \\
\mathrm{t}=1.32\end{array}$ \\
\hline YS & $\pm 6.7 \mathrm{MPa}$ & $\pm 7.1 \mathrm{MPa}$ & $\pm 8.2 \mathrm{MPa}$ & $\pm 11.6 \mathrm{MPa}$ \\
\hline UTS & $\pm 3.5 \mathrm{MPa}$ & $\pm 4.1 \mathrm{MPa}$ & $\pm 5.6 \mathrm{MPa}$ & $\pm 9.3 \mathrm{MPa}$ \\
\hline
\end{tabular}

\section{CONCLUSiOnS}

Results of the present investigation can be summarized in the following conclusions:

- The most significant contribution to measurement uncertainty comes from the number of samples tested, which can be even up to $1 \%$ as the number of tested samples is reduced down to only 3. In such case expanded measurement uncertainty at the confidence level of $95 \%$ increases way over $2 \%$.

- Moving from experimental laboratory conditions to ever intense industrial environment further amplifies measurement uncertainty. More severe machining conditions contribute $0.1-0.2 \%$ and automated gripping and positioning system around $0.1 \%$.

- In terms of measuring uncertainty, even if using automated systems, human error cannot be neglected. People working under intense pressure late in the afternoon and toward the end of the week are more likely to make mistakes. Just incorrect input of the sample diameter of just $0.1 \%$ will result in YS and UTS over or under estimation of $\sim 0.2 \%$ and incorrect placement of the specimen results in deviation of up to $0.8 \%$.

\section{REFERENCES}

[1] Palček, P., Porubčan, J., Blažek, D., Trojanová, Z. (2007). Internal friction in commercial aluminium alloy AW-2007. Procedia Engineering, 10, 12261231.

[2] Miller, W.S., Zhuang, L., Bottema, J., Wittebrood, A.J., De Smet, P., Haszler, A. (2000). Recent development in aluminum alloys for the automotive industry. Materials Science and Engineering A, 280, 37-49.

[3] Huang, J.C., Shin, C.S., Chan, S.L.I. (2004). Effect of temper, specimen orientation and test temperature on tensile and fatigue properties of wrought and PM AA6061-alloys. International Journal of Fatigue, 26, 691-703. 
[4] Zeng, L., Li, Z., Che, R., Shikama, T., Yoshihara, S., Aiura, T., Noguchi, H. (2014). Mesoscopic analysis of fatigue strength property of a modified 2618 aluminum alloy. International Journal of Fatigue, 59, 215-223.

[5] Ahuja, B., Karg, M., Nagulin, K.Y., Schmidt, M. (2014). Fabrication and characterization of high strength $\mathrm{Al}-\mathrm{Cu}$ alloys processed using laser beam melting in metal powder bed. Physics Procedia, 56, 135-146.

[6] Chen, D.C., You, C.S., Gao, F.Y. (2014) Analysis and experiment of 7075 aluminum alloy tensile test. Procedia Engineering, 81, 1252-1258.

[7] aluMATTER. 2xxx series alloys. http://aluminium.ma tter.org.uk/content/html/eng/default.asp?catid=214\&pa geid $=2144417081$.

[8] Magee, A., Ladani, L., Topping, T.D., Lavernia, E.J. (2012). Effects of tensile test parameters on the mechanical properties of a bimodal Al-Mg alloy. Acta Materialia, 60, 5838-5849.

[9] Podgornik, B., Leskovšek, V. (2013). Microstructure and origin of hot work tool steel fracture toughness deviation. Metallurgical and Materials Transaction A, 44, 5694-5702.

[10] Désenfant, M., Priel, M. (2006). Road map for measurement uncertainty evaluation. Measurement, 39, 841-848.

[11] Imai, H. (2013). Expanding needs for metrological traceability and measurement uncertainty. Measurement, 46, 2942-2945.

[12] Beckert, S.F., Domeneghetti, G., Bond, D. (2014). Using historical results obtained in the tensile tests for Type A evaluation of uncertainty. Measurement, 51, 420-428.

[13] Kuhinek, D., Zorić, I., Hrženjak, P. (2011). Measurement uncertainty in testing of uniaxial compressive strength and deformability of rock samples. Measurement Science Review, 11 (4), 112117.
[14] Joint Committee for Guides in Meteorology. (2008). Evaluation of measurement data - Guide to the Expression of uncertainty in measurement. JCGM 100:2008.

[15] Kessel, W. (2002) Measurement uncertainty according to ISO/BIPM-GUM. Thermochimica Acta, 382, 1-16.

[16] Klysz, S., Lisiecki, J. (2008) Selected problems of measurement uncertainty - Part I. Technical Sciences, 11, 253-264.

[17] Klysz, S., Lisiecki, J. (2008) Selected problems of measurement uncertainty - Part II. Technical Sciences, 11, 265-276.

[18] Tingdong, X., Hongyao, Y., Zhenjun, L., Zongwen, Z. (2015) The measurement uncertainty of reduction in area of metals in tensile testing system. Measurement, $66,1-9$.

[19] International Organization for Standardization. (2009). Metallic materials - Tensile testing - Part 1: Method of test at room temperature. ISO 6892-1.

[20] Levins, R., Lopez, C. (1999) Toward an ecosocial view of health. International Journal of Health Services, 29, 261-293.

[21] Spiegel, M.R. (1992). Theory and Problems of Probability and Statistics. McGraw-Hill, 116-117.

[22] metrology.wordpress.com. (2009). Student's t-factors. https://metrology.files.wordpress.com/2009/08/student s-t-factor.jpg.

[23] EURAMET e.V. (2011). Uncertainty of force measurements - Calibration guide, Ver. 2. http://www. euramet.org/Media/docs/Publications/calguides/EURA MET_cg-4_v_2.0_Uncertainty_of_Force_Measurem ents.pdf

[24] Gómez-Parra, A., Puerta, F.J., Rosales, E.I., GonzálezMadrigal, J.M., Marcos, M. (2013) Study of the influence of cutting parameters on the Ultimate Tensile Strength (UTS) of UNS A92024 alloy dry turned bars. Procedia Engineering, 63, 796-803.

Received September 20, 2015. Accepted January 28, 2016. 